\title{
CERÁMICA DE BARNIZ NEGRO DE ÉPOCA ROMANA REPUBLICANA EN YACIMIENTOS CELTÍBEROS Y CARPETANOS DE LA PROVINCIA DE GUADALAJARA
}

\author{
BLACK-GLAZED CERAMIC DATING FROM THE ROMAN REPUBLIC IN CELTIBERIAN AND \\ CARPETANIAN SITES IN THE REGION OF GUADALAJARA
}

\author{
EMILIO GAMO PAZOS \\ Universidad Complutense de Madrid \\ SANDRA AZCÁRRAGA CÁMARA \\ Universidad Autónoma de Madrid
}

\section{INTRODUCCIÓN}

Este artículo pretende actualizar el registro cerámico de época romana republicana en la provincia de Guadalajara pues el aumento del número de intervenciones arqueológicas realizadas en los últimos años ha permitido documentar gran cantidad de materiales importados con esta cronología. Su estudio resulta fundamental no solo para comprender el proceso de romanización en el interior peninsular, sino para subrayar el interés de la investigación en estas zonas, hasta este momento relegadas a un segundo plano.

Creemos que estas líneas añaden nuevos datos, muchos de ellos procedentes de yacimientos localizados durante las prospecciones realizadas recientemente por uno de nosotros en la provincia ${ }^{1} \mathrm{y}$ otros muchos resultado de la revisión realizada de materiales inéditos de época republicana conservados en el Museo de Guadalajara, y del intento de contextualización de todos ellos. El resultado ha sido la confección de un buen listado y un mapa de dispersión de los yacimientos con materiales importados de época romana republicana en la provincia de Guadalajara, que sirve de complemento al ya publicado para la Comunidad de Madrid (Azcárraga, 2007, 329). Subsana la anterior escasez de datos y la dispersión de materiales que impedía abordar el problema globalmente, como se comprueba en trabajos recientes (Carrasco, 2008).

1. Las prospecciones fueron realizas por Emilio Gamo durante el año 2010 en el marco del proyecto: «La época romana republicana en la actual provincia de Guadalajara: siglos II-I a.C.», Expediente: 100977. Financiado por la Consejería de Cultura, Turismo y Artesanía de la J. C. C. M.

\section{LOS YACIMIENTOS Y LOS MATERIALES ARQUEOLÓGICOS}

Describimos principalmente los hallazgos de cerámica de importación de época romana republicana en su contexto arqueológico, ordenando los yacimientos según criterio geográfico, desde el este del territorio hacia el oeste. Se ha adoptado el sistema de ficha sintética, incluida la bibliografía en la que se cita el yacimiento de alguna manera.

Hay que señalar que la actual provincia de Guadalajara estuvo ocupada por dos etnias diferentes: celtíberos y carpetanos ocupando la primera la mayor parte del área y la segunda solamente el extremo suroccidental del territorio, en los cursos medios del Tajo, Henares y Tajuña.

Prestamos especial atención a la cerámica de barniz negro de cronología y origen romano republicano que llegó al interior peninsular en sus diversas fases productivas: la campaniense $\mathrm{A}$, procedente de la isla de Ischia y el entorno de Nápoles, el barniz negro de Cales producción que corresponde, junto a la etrusca, a las conocidas como campaniense $\mathrm{B}$, que proceden de la Campania septentrional ${ }^{2}$ y la campaniense $\mathrm{C}$, procedente de Sicilia.

\section{OPPIDUM DE Los Rodiles (CUBILlejo de LA SIERRA)}

Este oppidum se sitúa en el extremo de una alargada loma en la margen sur del arroyo de la Vega en el

2. La Mesa Redonda sobre cerámicas de barniz negro de los siglos II-I a.C. realizada en Ampurias en 1998 (Aquilué et alii, 2000), supuso un avance importante en el estudio de estas cerámicas y en la «normalización» terminológica de la «Campaniense $\mathrm{B}$ » $\mathrm{y}$ a la acotación cronológica y formal de las diversas producciones. 


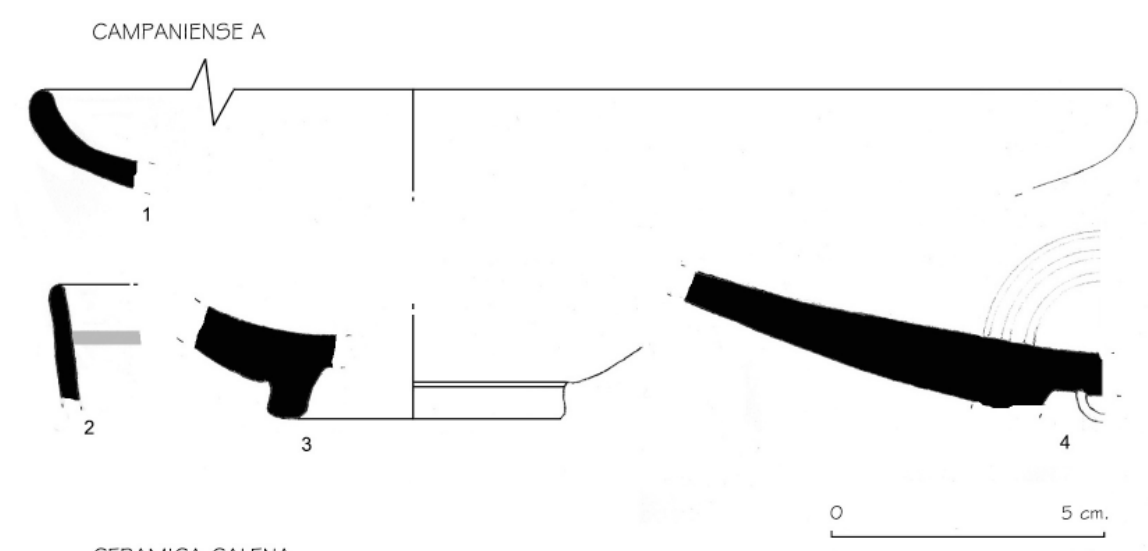

CERAMICA CALENA
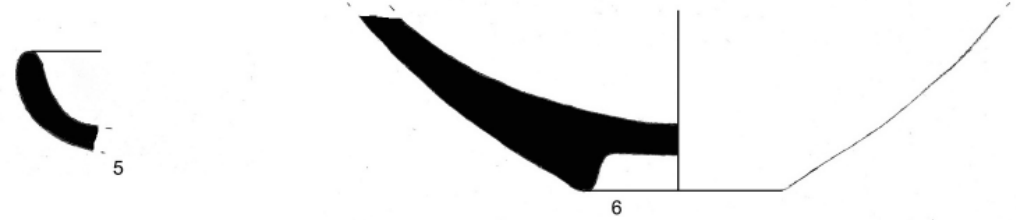

Figura 1: Cerámica de barniz negro del yacimiento de Los Rodiles II (Dibujo: S. Azcárraga).

centro de la depresión Tortuera-La Yunta. Está siendo excavado y estudiado por el equipo dirigido por M. L. Cerdeño desde el año 2006 y dichos trabajos están permitiendo definir con detalle un oppidum celtibérico de más de 3 hectáreas de extensión, rodeado de varios recintos defensivos concéntricos de aparejo ciclópeo.

El mayor interés radica en que se distinguen con claridad dos niveles de ocupación: el más antiguo, con una cronología desde el siglo III hasta comienzos del siglo II antes de la Era, fue destruido por un incendio que parece asociarse a las primeras operaciones militares romanas en esta área, seguramente las de $\mathrm{T}$. Sempronio Graco o Fulvio Flacco. El segundo nivel, más reciente, fechado durante gran parte del siglo II y hasta comienzos del siglo I antes de la Era, se abandonó cuando los celtíberos se vieron obligados a reestructurar el hábitat al finalizar el conflicto sertoriano. Durante esta segunda ocupación se realizaron ampliaciones y remodelaciones del recinto amurallado, se encuentran en la acrópolis viviendas ya con un diseño interno complejo y es donde se localiza la cerámica de importación romana.

Durante una primera prospección (Arenas, 1999) se localizaron 5 fragmentos de barniz negro de Cales, 4 de ellos indeterminados y uno perteneciente a la forma 2255a de Morel, es decir, una pátera de la forma Lamb. 5, que se da en la producción calena en sus fases media o tardía.

Las cuatro campañas sistemáticas de excavación han ampliado los datos pues no solo aparece cerámica calena, sino también campaniense A en mayor proporción. En la campaña de excavación de 2006 se documentaron algunos fragmentos indeterminados de campaniense A, tanto media (190/180-100 a.C.), como tardía (100-50/40 a.C.) (Fig.1). Aunque el material aparece bastante fragmentado, podemos distinguir varias formas diferentes. De los 6 fragmentos que aportan una tipología formal, cuatro son campaniense A y el resto cerámica calena.

Dentro de la campaniense A de la producción de la fase media, fechada entre el 190/180 y el 100 a.C., encontramos tres fragmentos: el primero es un borde de pátera Lamb. 5/F2252 (Fig. 1.1); el segundo pertenece a una copa con asas M 68bc/F 3131, decorado con una línea blanca al interior, decoración típica de esta producción y heredada de la variante antigua (Fig. 1.2); el último es una base anular con arranque de la pared podría corresponder probablemente a una Lamb. 27ab o 27 c. (Fig. 1. 3). A la producción de la fase tardía de campaniense A, fechada entre el $120 / 100^{3}$ y el $50 / 40$ a.C. pertenece un fragmento de plato/pátera, que es probable que se trate de una Lamb. 5, 6 o 36 (Fig. 1.4).

En cuanto a la producción calena de barniz negro, los dos fragmentos identificados se corresponden con la fase media de dicha producción, ubicada entre el 130/120 y el 90/80 a.C.; el primero coincide con la forma Lamb.5, en esta ocasión la forma 2252 de Morel (Fig. 1. 5) y el segundo fragmento con una copa Lamb.33b/F2153 (Fig. 1.6). En el trascurso de las excavaciones se documentaron también fragmentos de ánforas vinarias del tipo Dressel $1 \mathrm{~A}$.

- Bibliografía: Arenas, 1999, 277; Cerdeño et alii, 2008, 175; Cerdeño et alii, 2010; Valiente y Velasco, 1988.

3. El inicio de esta fase se sitúa entre el 120/100 a.C. según algunos autores (Asensio y Principal, 2006, 124) mientras que otros abogan por una fecha en torno al 100 a. C (Py, 1993,146). 


\section{Villa de la Vega (Cubillejo de la Sierra)}

Se sitúa en una llanura dedicada actualmente a las labores agrícolas en la margen derecha del arroyo de la Vega. Las estructuras conservadas están afectadas por la acción del arado y en superficie sólo se observan sillares escuadrados, tegulae, molinos circulares rotatorios y fustes de columna que muestran cierta monumentalidad en esta pars urbana de la villa, probablemente dotada de patio con peristilo; en las fotografías aéreas se observa la planta de un edificio de planta cuadrangular.

Aunque no se han realizado trabajos sistemáticos, este yacimiento ha proporcionado en superficie abundantes cerámicas entre las hay de barniz negro, paredes finas, terra sigillata gálica, terra sigillata hispánica lisa y decorada, así como T. S. H. T. A la vista de los restos cerámicos conservados, la cronología de la villa podría estimarse en un arco desde época tardo-republicana (siglo I a.C.) hasta el periodo bajo imperial e incluso tardoantiguo.

La cerámica de barniz negro aparece mencionada en la bibliografía desde la primera prospección, donde se hablaba de un fragmento de «campaniense B», forma 7541a de Morel (Arenas, 1999, 277); se trata, por tanto, de un píxide de la forma Lamb. 3, típico de la producción calena en sus fases media o tardía.

- Bibliografía: Arenas, 1999; Cerdeño et alii, 2008; Cerdeño y Gamo, 2009; Valiente y Velasco, 1988.

\section{Castro del Castil de lobos (Alustante)}

Situado sobre un espolón calizo, en cuya parte más alta hay un yacimiento de la I Edad de Hierro y en la parte baja se ubica un asentamiento celtíbero-romano que continuó ocupado hasta época romana imperial. Se conoce por prospección cuando se elaboró la Carta Arqueológica (Arenas, 1999, 108).

No se ven con claridad restos de muralla, ni de foso, en cambio, si se distinguen estructuras de viviendas angulares. En cuanto al material importado, solo conocemos la presencia de un asa de ánfora vinaria itálica del tipo Dressel 1.

- Bibliografía: Arenas, 1999, 108.

\section{Castro de Las Hoyas (Anquela del Pedregal)}

Está ubicado sobre un cerro de $1320 \mathrm{~m} \mathrm{s.} \mathrm{n.} \mathrm{m.} \mathrm{y} \mathrm{con-}$ serva los restos de un muro perimetral de cierre. Es interesante el resaltar que a los pies de este yacimiento se encuentra un gran escorial.

Este yacimiento solo se conoce por prospección, en la cual se documentó un fragmento de campaniense $\mathrm{C}$ de forma indeterminada, que otorgaría una cronología general del siglo II-I a.C.

- Bibliografía: Arenas, 1999, 108, 277.

\section{Castro de El Castillejo (Anquela del Pedregal)}

Sobre un cerro de orientación este-oeste que se eleva 1437 m s. n. m., ocupa una extensión de 0,67 hectáreas. El hábitat posee dos recintos amurallados, que en algunos tramos tienen aparejo ciclópeo; dentro del recinto defensivo se ubican estructuras de habitación. El hábitat se conoce exclusivamente por prospección.

Parece ofrecer un amplio espectro cronológico que abarca desde el periodo Celtibérico Antiguo hasta el siglo I de la Era. Según pudimos observar en el Museo de Guadalajara, se conserva abundante material cerámico que incluye cerámica a mano con decoración grafitada y plástica, cerámica celtibérica a torno, alguna de ellas con decoración pintada, cerámica común romana, T. S. Itálica e Hispánica.

También contamos con la referencia bibliográfica a un fragmento de «campaniense B» de la forma 2566a de Morel, por tanto, un cuenco de la forma Lamb. 1/8 típico, de la producción calena en sus fases media o tardía.

- Bibliografía: Arenas, 1999, 109-110, 277; GarcíaHuerta, 1990, 90-91.

\section{Poblado de Villarejo I (Morenilla)}

Está situado en la margen derecha del Río Gallo en una ladera dedicada al cultivo de secano, separada del cauce del río por un barranco. Fue localizado durante las prospecciones para la elaboración de la Carta Arqueológica de Morenilla.

No se observan estructuras constructivas en superficie pero si se localizaban, movidos por la acción del arado, restos de piedras y tegulae, así como una gran mancha cenicienta y un escorial.

El yacimiento ofrece un amplio marco cronológico, desde época romana republicana hasta alto imperial y bajo imperial, perviviendo por lo menos hasta el siglo V de la Era como indica la presencia de T. S. H. T. decorada con motivos geométricos propios del «segundo estilo». Hay noticias de la presencia de un fondo de cerámica campaniense, del cual no contamos por el momento con más información (comunicación personal de J. Arenas).

- Bibliografía: Gamo, 2011, 104-111.

\section{Castro de La Coronilla (Chera)}

Situado sobre un cerro testigo junto al río Gallo, en la primera vega de su margen derecha. Fue excavado sistemáticamente durante los años 1980-1986 (Cerdeño y García-Huerta, 1992).

Conservaba una primera ocupación durante la I Edad de Hierro o Celtibérico Antiguo, un momento de abandono y una posterior reocupación en el siglo II antes de la Era, para continuar ocupado hasta el siglo I 
de la Era, siendo la mayoría de materiales de los siglos II-I a.C. También parece que tuvo una reocupación de época alto medieval.

Durante la ocupación celtíbero-romana parece que hubo remodelaciones y reformas de las estructuras pétreas. Tiene una ordenación urbanística de «calle central», existiendo un muro perimetral de cierre que se encuentra muy perdido por el derrumbe de las cornisas. A dicho muro de cierre se adosan las traseras de las viviendas cuyos muros le son perpendiculares.

Se encontraron un total de 12 habitaciones rectangulares con una superficie entre los 15 y los 36 metros cuadrados, que se elevan sobre un zócalo de mampostería de unos 50 centímetros de altura, así como un alzado de adobe o tapial que en su interior estaba enlucido; los suelos son de tierra de color blanquecino.

Durante las excavaciones se recogieron numerosos fragmentos de cerámica celtibérica a torno, destacando cuencos, platos, kalathos decorados con motivos vegetales y grandes vasijas de almacenamiento de cuerpo globular. Mención aparte merece la numismática, ya que se recogieron dos ases de la ceca de sekaisa, un as de Calagurris de época de Octavio y un denario de bolskan.

En cuanto a la cerámica importada, destaca la aparición de dos fragmentos de una crátera de campana del siglo IV a.C., cuya presencia puede interpretarse en clave de perduración. La cerámica común romana está representada por la forma Vegas 1 y las paredes finas por la forma Mayet. Hay terra sigillata itálica, uno de los fragmentos con el sello de «CN. ATEI» propios de un taller de Arezzo del último cuarto del siglo I a.C. y un asa de ánfora Dressel 1.

La cerámica de barniz negro apareció en la vivienda $\mathrm{n}^{\mathrm{o}} 3$ con un fragmento de borde de una pátera Lamb. 5, forma muy común en la cerámica calena. En la vivienda $n^{\circ} 4$, dos fragmentos de «campaniense $B$ » (como aparece citada en la bibliografía) del mismo recipiente, una copa Lamb. 4/ F1413f1 que por sus características parece una producción media de la cerámica calena y se ubicaría entre el 130/120 y el 90/80 a.C. En la vivienda $\mathrm{n}^{\mathrm{o}} 12$ aparecieron dos fragmentos de campaniense A y uno del tipo B, aunque no se precisan sus formas. En total se documentaron 22 fragmentos entre campaniense A y B.

- Bibliografía: Cerdeño y García-Huerta, 1982; Cerdeño y García-Huerta, 1992; Lázaro, 1993-95.

\section{Necrópolis del Puente de la Sierra (Checa)}

Se ubica en el centro de un valle regado por el arroyo La Pedrera, en las cercanías del hábitat en alto de Castil Griegos, ocupando un área de unos $5000 \mathrm{~m}^{2}$ que se están excavando desde el año 2005 (Martínez y de la Torre, 2006).
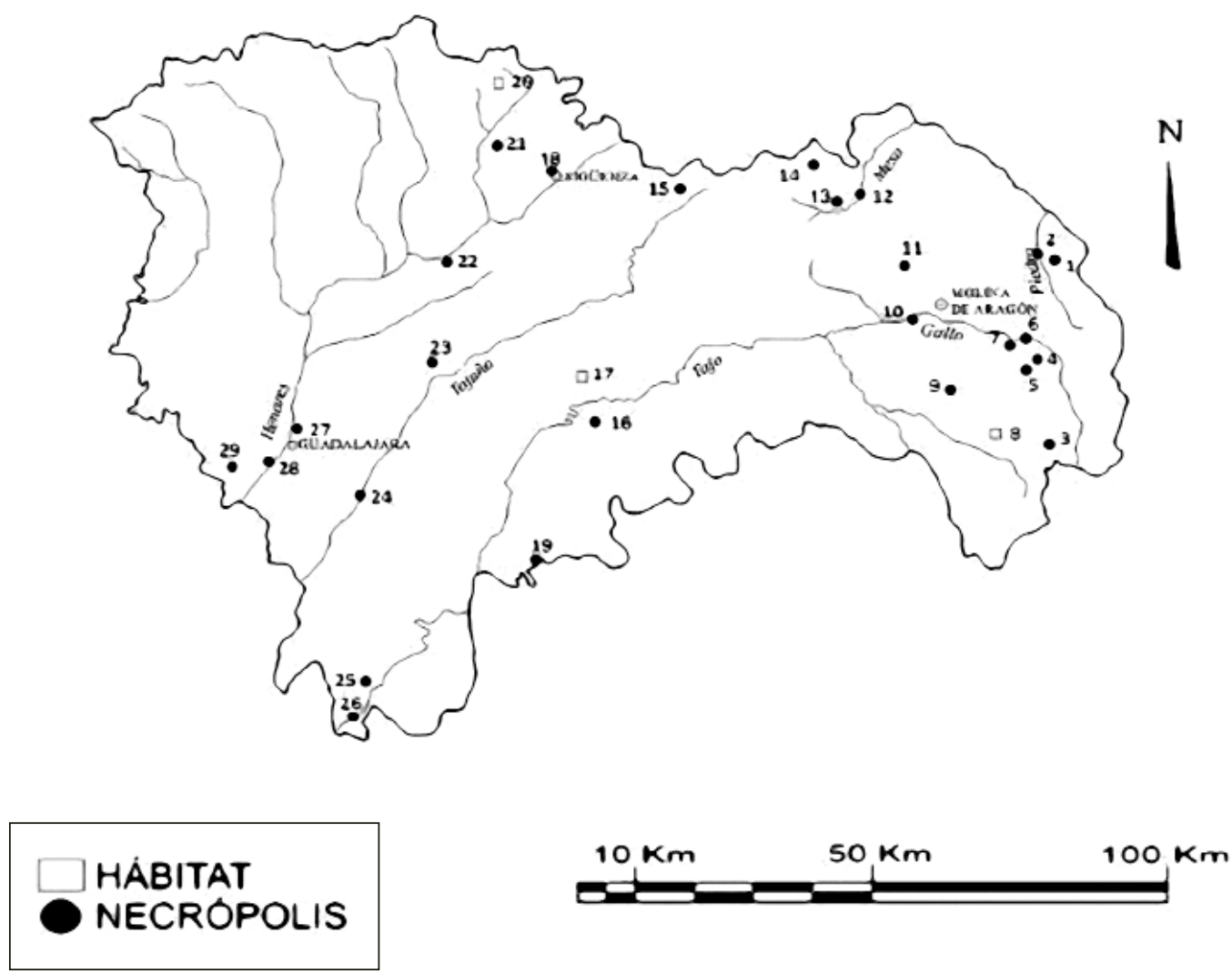

Figura 2: Ubicación de los yacimientos mencionados en el texto. 
Tiene tres niveles de uso con un arco cronológico entre el siglo V y el I antes de la Era. El momento más reciente es de época celtíbero-romana, siglos II-I a.C., el espacio está ordenado en «calles» de tumbas alineadas y sus ajuares muestran una llamativa ausencia de elementos armamentísticos como es característico de las necrópolis del Celtibérico Tardío.

En cuanto al material cerámico importado, destaca la presencia de una copita Lamb. 25 decorada con palmetas estampilladas y clasificada como «campaniense $\mathrm{B} »$. Esta forma surge en la etapa antigua de la campaniense A (220-190/180 a.C.) pero permanece hasta la fase media (190/180-100 a.C.). El resto de los fragmentos de barniz negro - un oinochoe y varias asas de distintos recipientes indeterminados- se atribuyen a un silicernia.

-Bibliografía: Martínez y de la Torre, 2006.

\section{Castro de El Castillejo I (Terzaga)}

El Castro está sobre un cerro amesetado a $1240 \mathrm{~m} \mathrm{s.} \mathrm{n.}$ $\mathrm{m}$., se conoce sólo por prospección. Tiene un recinto amurallado precedido por un foso y también se conservan los restos de una estructura turriforme de época medieval islámica. En el interior del recinto amurallado se atisban estructuras de vivienda.

Los materiales de superficie indican una ocupación protohistórica desde el Celtibérico Antiguo hasta la época romana-republicana. Se identificó un fragmento de «campaniense B» de la forma 2565 b de Morel, es decir, un cuenco de la forma Lamb. 1/8 típico, como ya hemos señalado de la producción calena en sus fases media o tardía. Este fragmento presenta una peculiaridad en su decoración, una línea blanca pintada al interior del borde, un tipo de decoración propia de la campaniense A.

- Bibliografía: Arenas, 1999, 108, 277.

\section{Castro de El Castellote (Corduente)}

Esta el yacimiento sobre un cerro aislado, con una altura de $1158 \mathrm{~m} \mathrm{~s}$. n. m., en la vega del río Gallo en su margen derecha. Conocido por prospección, muestra en superficie vestigios de una muralla de cierre perimetral.

Contamos con la información de una campaña de prospecciones en la que se documentó, además de material a mano y de cerámica celtibérica con motivos pintados geométricos, un fragmento de pared de barniz negro (García-Huerta, 1989). Tras localizarla en el Museo de Guadalajara, hemos podido constatar que se trata de un fragmento de cerámica calena media (130/120-90/80 a.C.) o tardía (90/80-40/20 a.C.) perteneciente al fondo de una pátera, probablemente una Lamb. 5.

- Bibliografía: Arenas, 1999, 108, 277; Gamo, 2011, 26-35; García-Huerta, 1989, 11.

\section{Castro de Las Coronillas I (Pardos)}

Ubicado sobre un espolón a 1200 m s. n. m., se conoce sólo por prospección. Conserva una muralla de paramento ciclópeo que rodea el hábitat por todos sus flancos excepto por el norte; dicha muralla se encuentra precedida por un foso excavado en la roca en su flanco sur.

En distintas publicaciones se menciona el hallazgo de un fragmento de «campaniense B» de la forma 2286 a de Morel (Arenas, 1999,108), por tanto, de una pátera de la forma Lamb. 7, forma más típica en las producciones de campaniense $\mathrm{C}$.

- Bibliografía: Arenas, 1998; Arenas 1999, 108, 277; Martínez, 2002.

\section{Castro de Hoyo Redondo II (Anchuela Del CAMPO)}

Sobre una elevación a 1180 m s.n. m., es conocido exclusivamente por prospección y apenas se distinguen restos constructivos en superficie. Los materiales cerámicos recuperados son mayoritariamente de cerámica a torno celtibérica, alguna con decoración pintada.

Se mencionan fragmentos de ánforas itálicas y un fragmento de «campaniense B» de la forma $2323 \mathrm{~h}$ o 2361 a de Morel, es decir, un cuenco de la forma Lamb. 1 típico, también, de la producción calena en sus fases media o tardía.

- Bibliografía: Arenas, 1999, 108, 277.

\section{Castro de La Torre II (Turmiel)}

Está enclavado sobre un cerro a $1180 \mathrm{~m} \mathrm{s.} \mathrm{n.} \mathrm{m.} \mathrm{que}$ controla la extensa vega del río Mesa. Es conocido por prospección y apenas se conservan restos constructivos en superficie. Existe un fragmento de «campaniense $\mathrm{B}$ » de forma indeterminada, el cual otorga una cronología general del siglo II-I a.C.

- Bibliografía: Arenas, 1999, 108, 277.

\section{Poblado de Modojos II (Codes)}

Se ubica sobre una elevación de $1180 \mathrm{~m}$ s. n. m. y es conocido por prospección exclusivamente. No se distinguen con claridad estructuras constructivas en superficie, por la alteración causada durante las tareas agrícolas. Además de cerámica celtibérica, se localizó en superficie el borde de un ánfora vinaria itálica, del tipo Dressel 1.

- Bibliografía: Arenas, 1999, 108.

\section{La Cerca (Aguilar de Anguita)}

Se localiza sobre una extensa loma en la margen derecha del río Tajuña, ocupando el recinto una extensión 
de 12 hectáreas. Este yacimiento fue excavado en la segunda década del siglo XX por el Marqués de Cerralbo que puso al descubierto un recinto amurallado con cuatro puertas de acceso y con escaleras interiores. Recientemente se ha vuelto a excavar de manera sistemática y se ha descrito el recinto fortificado como construido a la manera itálica, aunque los autores no creen que corresponda a un estructura campamental (Gorgues y Rubio, 2010).

En un primer momento fue identificado como campamento romano, aunque posteriores estudios (Sánchez-Lafuente, 1979) han abierto otras posibilidades de interpretación como la de ser un oppidum celtibérico reutilizado posteriormente. El debate sobre el significado y función de este yacimiento sigue abierto en la actualidad.

Existen materiales de la intervención de Cerralbo depositados en el M. A. N. que incluyen fragmentos de campaniense A con estampillas y un plato de cerámica de Cales (Barril y Salve, 1998, 62).

- Bibliografía: Aguilera, 1911, 9; Aguilera, 1916, 86; Argente, 1977, 597; Barril y Salve, 1998; SánchezLafuente, 1979; Schulten, 1929, 191.

\section{Poblado de las Tetas de Viana- Teta Redonda (Viana De MondÉJar)}

El yacimiento se extiende sobre dos cerros testigos paralelos. La Teta Redonda situada al suroeste está separada por un collado de la situada al noreste. Ambas elevaciones tienen una altura de $1114 \mathrm{~m} \mathrm{s.} \mathrm{n.} \mathrm{m.}$ Realmente se trata de dos yacimientos que se ubican a distinta altura de la ladera sur. Se conocen exclusivamente por prospección.

Apenas se distinguen en superficie estructuras constructivas antiguas previas a la Edad Media, aunque existen noticias referidas a antiguos hallazgos de «pavimentos romanos» en este lugar. El yacimiento que llamamos Teta Redonda I es un hábitat celtibérico que tiene continuidad en época romana republicana pues documentamos en el Museo de Guadalajara dos galbos de cerámica de barniz negro, en concreto calena media (130/120-90/80 a.C.). Uno de los galbos pertenece a un plato Lamb. 5 y el otro es un fragmento cercano al arranque del pie, y podría tratarse de un bol Lamb. 1 o similar.

El segundo yacimiento, llamado Teta Redonda II, probablemente se sitúe a media ladera por el hallazgo de un lote de T. S. H. T. (López, 1985, 178-179), algunas con decoración burilada así como otras del primer y segundo estilo, indicadoras de una cronología romana bajo imperial, entre los siglos IV y V de la Era. También se encontró un único fragmento de terra sigillata hispánica alto imperial decorada. Igualmente se localizó cerámica común romana y el asa de una lucerna.

- Bibliografía: Abascal, 1982, 95-96; García, 1964, 361; López, 1985; Martínez y Valiente, 1990; Pavón,
1984, 179; Sánchez-Lafuente, 1987，181; Valiente, 1997, 97-100.

\section{Necrópolis de El Plantío - El Almagral (Ruguilla, Cifuentes)}

Se identificaron dos espacios necropolitanos en el entorno de la localidad de Ruguilla, que fueron excavados hace ya un siglo. Las noticias de ambos yacimientos se confunden así como los materiales depositados en el M. A. N., que se conservan de forma fragmentaria. La primera excavación de las necrópolis de Ruguilla fue realizada a finales del siglo XIX por Francisco Rafael de Laurecín, Marqués de Uhagón y posteriormente, entre 1912-1914, el Marqués de Cerralbo realizó excavaciones arqueológicas en ambas necrópolis «El Plantío» y «El Almagral», dato que conocemos por las etiquetas conservadas en el M. A. N.

Vecinos del pueblo nos indicaron amablemente que durante las obras de mantenimiento de la carretera entre Rugilla y Sotoca se localizaron restos de ceniza y urnas, algunas de ellas completas, cuyo paradero actual desconocen. Por su parte, Argente documentó en los fondos del M. A. N. un total de 7 fíbulas -3 de doble resorte, 2 anulares hispánicas, una de pie vuelto y otra de La Tène- supuestamente procedentes del yacimiento, que indican un arco cronológico entre los siglos V y el II a.C.

En cuanto a la cerámica importada, hay noticias difusas de García y Bellido que dice: «Noticia de un kylix campaniense en la colección del Marqués de Cerralbo»; lo más probable es que se trate de una cerámica ática, ya que dicha forma es típica de su repertorio y conocida desde antiguo.

- Bibliografía: Aguilera, 1916; Argente, 1977, 596; Argente, 1994, 475-477; Cabré, 1920, 254; García, 1936, 125; Huagón, 1893, 347-348.

\section{Iglesia de Nuestra Señora de los Huertos (SIGÜENZA)}

La iglesia de Nuestra Señora de los Huertos se encuentra en la parte baja de Sigüenza, en la margen izquierda del río Henares, junto a la Alameda. Durante las excavaciones llevadas a cabo en el atrio de esta iglesia entre 2004-2005 (Ferrero y García-Soto, 2007), se recuperaron restos arqueológicos romanos, pero en una estratigrafía revuelta.

En los sondeos dos y tres de las mencionadas intervenciones, aparecieron una serie de materiales romanos, no así estructuras, mostrando un amplio arco cronológico. Se documentaron varios fragmentos de cerámica campaniense C, T. S. H. alto imperial, cerámica pintada de tradición indígena, cerámica común, T. S. H. T., tegulae y fragmentos de vidrio.

- Bibliografía: Ferrero y García-Soto, 2007. 


\section{OpPidum de la Muela de Alcocer (Alcocer)}

Está enclavado sobre una llanura amesetada en la margen derecha del río Guadiela y por la construcción del pantano de Buendía ha quedado actualmente como una península. Su extensión es de 8,6 hectáreas y se alza a una altitud de 737 m s. n. m. Conocemos este hábitat únicamente por prospección.

En su mitad este, se localizan restos del recinto amurallado perimetral, de mampostería y muy afectado por las tareas agrícolas que, por otra parte, dejan en superficie restos de adobes y sillares pertenecientes a estructuras habitacionales.

De este lugar procede un proyectil de honda de plomo en el que se lee: «Q. SERT. PROCOS» (Fuentes, 1993, 174), dos ases -sin más indicaciones- y un denario de la ceca de bolskan (Pérez, 1974, 38). El único material cerámico publicado pertenece a una colección particular entre la que destaca la presencia de un fragmento de campaniense A y dos fragmentos más de tipo B, correspondientes a 2 páteras de las formas Lamb. 5 y Lamb. 6. En el mencionado lote también se documentaron ánforas del tipo Dressel $1 \mathrm{~A}$ de producciones campanas, un fragmento de mortero itálico de la forma Emporiae 36.2, cerámica común romana de época augústea y un fragmento de terra sigillata itálica de la forma Ettlinger 1990, 33.

Durante nuestras prospecciones de 2010, localizamos numerosos fragmentos anfóricos, en su mayoría Dressel $1 \mathrm{~A}$, pero también un ánfora del Levante de la Península Ibérica (Fig. 3.2) y otra de Brindisi ${ }^{4}$ (Fig. 3.1). Según los materiales recuperados, tuvo una cronología centrada en época romana republicana y, aunque parece que comenzó a despoblarse tras el conflicto sertoriano, tuvo una población residual hasta época augústea.

Lorrio (2001) propuso que la Ercavica celtibérica tuvo su solar en este oppidum situado a 6 kilómetros del castro de Santaver, aguas arriba del Guadiela, y que fue tras el conflicto sertoriano cuando hubo un trasvase de población desde la Muela de Alcocer hasta el Castro de Santaver.

- Bibliografía: Fuentes, 1993, 174; Gamo 2011b; Lorrio, 2001; Pérez, 1974, 38

\section{NeCRÓPOlis de VAldenOVILlos (Alcolea dE LAS PEÑAS)}

El yacimiento fue excavado por el marqués de Cerralbo en el año 1916 que exhumó al menos 103 tumbas, según se desprende de las etiquetas conservadas en el M. A. N. en alguna de las cuales se mencionan «calles».

4. Agradecemos a Rui Roberto de Almeida sus indicaciones acerca de las características de estas piezas.
En un trabajo muy posterior, Cerdeño (1976) pudo identificar 20 ajuares de tumbas como conjuntos cerrados a partir de los materiales conservados en dicho centro y propuso una cronología para el yacimiento entre los siglos VII-III a.C. ya que, ciertamente, muchos de los materiales metálicos (espada de antenas atrofiadas, determinadas fíbulas, broches de cinturón, etc...) pueden incluirse en ese arco cronológico.

Sin embargo, una minoría de materiales remite a una continuidad en el uso de la necrópolis hasta el siglo I antes de la Era ${ }^{5}$. Entre estos materiales se encuentra una fíbula de la Tène III del tipo $8 \mathrm{C}$ de Argente cuya cronología remite al siglo I a.C. En cuanto al barniz negro, hay mención de la presencia de un cuenco de «campaniense $\mathrm{B}$ » de la forma Lamb. 1 con dos grafitos, forma característica de las fases media y tardía del barniz negro caleno, que abarca un abanico cronológico entre el 130 y el 20 a.C.

- Bibliografía: Aguilera, 1916, 17, 57, 58; Argente, 1977, 587-598; Argente, 1994, 368-382; Bosch, 1921; Cerdeño, 1976; García-Huerta, 1990, 153-155; Maluquer, 1954; Schüle, 1969, 257.

\section{Cerro del Padrastro (Santamera)}

Situado en un alto cerro testigo calcáreo de difícil acceso, de cumbre amesetada, en la margen derecha del río Salado, alcanza los 1099 m s. n. m. Ofrece una posición sumamente estratégica dominando el desfiladero sobre el valle del Río Salado y las salinas de Gormellón.

Se conoce por prospecciones en superficie en la que se observan estructuras de un muro perimetral de cierre que se refuerza con una estructura turriforme. A tenor de los hallazgos cerámicos, podemos afirmar que es un hábitat con un largo periodo de ocupación desde la Edad de Bronce Final, con materiales característicos de Cogotas I, y las facies de Sotodosos - Riosalido hasta época celtibérica.

El lugar volvió a ocuparse en época romana bajo imperial, entre los siglos IV y V, se encontraron múltiples fragmentos de T. S. H. T. Durante las prospecciones realizadas en 1983 (Valiente, 1992, 40), se señaló la presencia de un fragmento de campaniense. Pero tras revisarlo en el Museo de Guadalajara, hemos constatado que se trata de un fragmento indeterminado de cerámica ática, por lo que en principio no se documentaría la ocupación del yacimiento en época republicana.

- Bibliografía: Valiente, 1992, 40.

5. La perduración en el uso de la mayoría de las necrópolis celtibéricas de la Meseta Oriental durante época romana republicana es un fenómeno que se está constatando arqueológicamente en múltiples yacimientos de la provincia (Gamo, 2011). 


\section{El Castro (Bujalaro)}

Se trata de un hábitat sobre una alargada loma, en cuya ladera sur se ubica el pueblo actual. Por el norte fluye el río Henares y por el oeste el arroyo de Fuente Rey. El yacimiento es conocido solamente por prospección, ocupa un área de 2'547 hectáreas y conserva algunos restos constructivos del recinto defensivo, así como zócalos de viviendas de planta rectangular.

Son abundantes los fragmentos cerámicos de la II Edad de Hierro, mientras que de época romana se conservan tres fragmentos de cerámica de barniz negro y otro de T. S. H., así como un denario de la ceca de bolskan.

- Bibliografía: Gamo, 2011, 226-235; Morère, 1983, 31.

\section{Llano de San Pedro-Las Viñas (VALDERREBollo)}

Importante oppidum ubicado en la margen derecha del río Tajuña, en una amplia llanura amesetada a una altitud de $900 \mathrm{~m}$ s. n. m. Tiene una extensión de 9,38 hectáreas y en el lugar se realizaron hallazgos arqueológicos a mediados del siglo XIX, cuando un farmacéutico de Brihuega, llamado Fernando Sepúlveda, desarrolló una serie de excavaciones arqueológicas, de las cuales envió una memoria a la Real Academia de la Historia.

Durante nuestras prospecciones de 2010, localizamos el lugar donde se habían efectuado los hallazgos en el siglo XIX y constatamos los restos de una muralla con tramos de aparejo ciclópeo, aunque gravemente alterada por las tareas agrícolas; igualmente encontramos numerosos fragmentos de cerámica celtibérica a torno, cerámica común romana y un fragmento de cerámica de barniz negro. En cuanto a este último fragmento, se trata de un galbo de cerámica calena tardía (Fig. 3.4), perteneciente a un cuenco de la forma Lamb.1 o similar, con una cronología asignada entre el 90/80-40/20 a.C. Confirmamos que este yacimiento es uno de los principales asentamientos de las últimas fases de la cultura celtibérica en esta área; un hábitat de la II Edad de Hierro que continúa ocupado durante época romana republicana, llegando hasta las primeras décadas del siglo I.

F. Sepúlveda describe en sus epístolas a la R. A. H. el hallazgo de numerosos objetos metálicos: hoces, azadas, bocados de caballo, puntas de lanza, flechas, llaves, tijeras y pinzas de hierro; dos diademas de plata y cuatro brazaletes del mismo metal, así como «una hebilla de oro, de poco peso, como de un tahalí». También dio noticia de un amplio lote de monedas (ases y denarios) de las cecas de leyenda indígena: arekorata, arkailikos, arsaos, baskunes, bilbilis, bolskan, ekualakos, inkesankom kombouto, iltirta, karaues, kelse, kontrebia karbika, sekobirikes, titiakos, turiasu; igualmente dio razón de monedas de: Bilbilis,
Calagurris, Celsa, Caesaraugusta, Emporie, Ercavica, Gracurris, Osca, Segobriga y Turiaso.

- Bibliografía: Abascal, 1995; Gamo, 2011.

\section{Castro del Cerro Alvarfañez (Romanones)}

Está enclavado en un cerro sobre la margen izquierda del río Tajuña y es conocido desde antiguo aunque sólo por prospección. Se trata de un poblado carpetano que continuó frecuentado durante el período romano republicano.

De este lugar proceden abundantes fragmentos de cerámica carpetana a torno, algunos de ellos decorados con pintura monocroma y motivos geométricos y en el Museo de Guadalajara pudimos estudiar un fragmento de borde, probablemente de campaniense $\mathrm{C} \mathrm{o}$ imitación, de pasta gris y con el barniz muy perdido, correspondiente a una escudilla de la serie 2310 de Morel, con cronología del siglo I a.C.

- Bibliografía: Abascal, 1982, 89-90; Ceán-Bermúdez, 1889, 135.

\section{Poblado de la Vega del Tajo junto a Valdealcalá - San Benito (Almoguera)}

Localizado en una llanura a la orilla derecha del río Tajo, se ubica en terrenos de labor a los pies del yacimiento celtíbero-romano del Cerro de Valdealcalá, al otro lado del arroyo del mismo nombre. No se conservan estructuras constructivas in situ, pues las tareas agrícolas han antropizado fuertemente el entorno.

El yacimiento sólo se conoce por prospección y los materiales que pudimos estudiar en el Museo de Guadalajara procedían mayoritariamente de las prospecciones realizadas para la Carta Arqueológica de Almoguera. Los hallazgos numismáticos incluyen un as de Augusto y medio centenional de Constantino II $\mathrm{y}$ entre los objetos de bronce cabe destacar un amuleto fálico y de plomo pesas de red para pesca, así como un peso de plomo cuadrangular.

Se documenta gran variedad material cerámico: celtibérico, un fragmento de campaniense C, T.S. gálica, T. S. H. alto imperial lisa y decorada, algunas con grafitos, T. S. H. T., sigillata clara, cerámica pintada de tradición indígena, cerámica común romana, cerámica de paredes finas, pesas de telar y tegulae. Hay un fragmento de barniz negro indeterminado de campaniense $\mathrm{C}$, con pasta gris y barniz denso y brillante.

Los materiales conservados ofrecen un amplio marco cronológico que abarca desde época tardo-republicana hasta el Bajo Imperio, por lo que se podría proponer una fecha entre mediados del siglo I antes de la Era y por lo menos el siglo IV de la Era. En cualquier caso el hábitat parece tomar especial pujanza en época alto imperial, entre los siglos I-II de la Era. - Bibliografía: Gamo, 2009. 


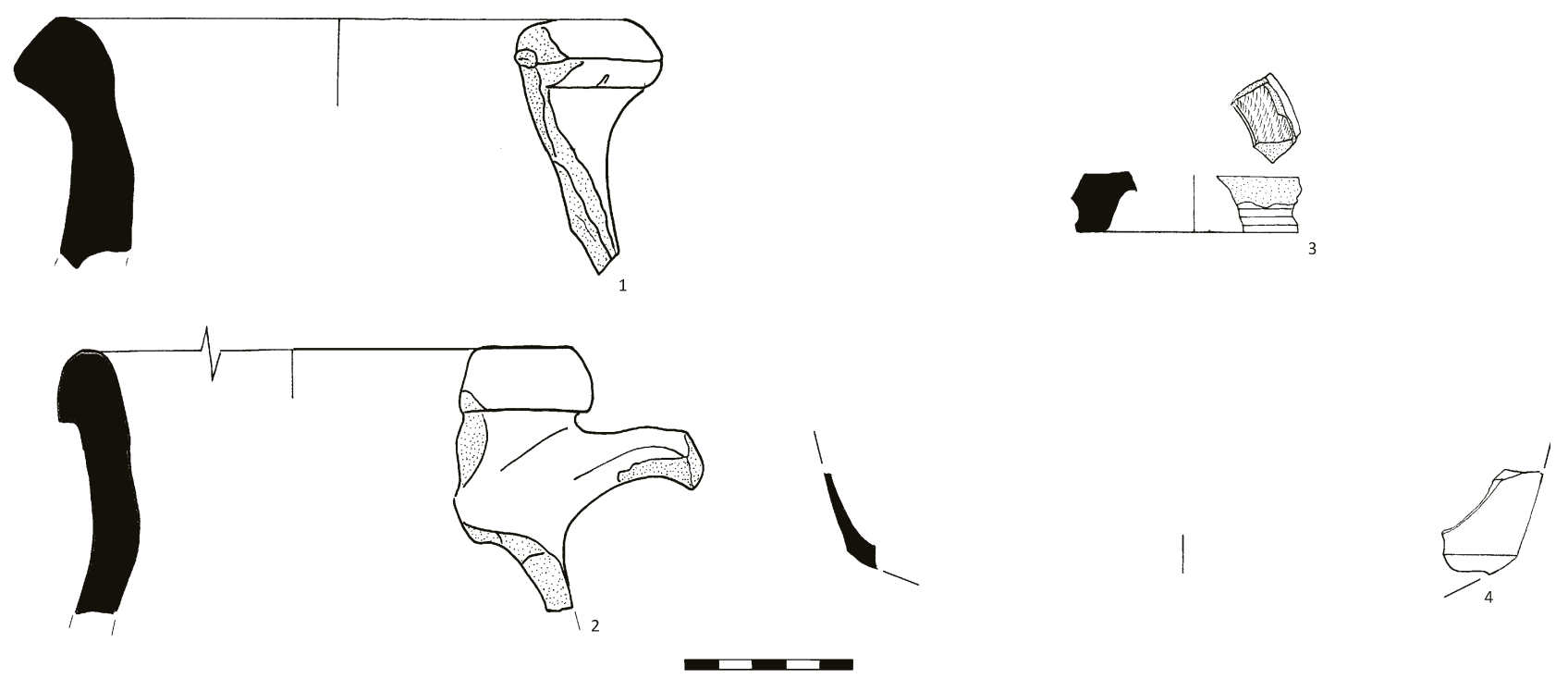

Figura 3: Selección de cerámica romana de importación: 1- Ánfora de Brindisi (Muela de Alcocer); 2- Ánfora levantina (Muela de Alcocer); 3- Pie de campaniense C, probable copa Lamb. 17/ F 1255a 1 (Cerro de la Virgen de la Muela, Driebes); 4-Cerámica calena tardía (Llano de San Pedro, Valderrebollo) (Dibujo: J. M. Higueras).

\section{OpPidum del Cerro de la Virgen de la Muela (DRIEBES)}

Está ubicado sobre un amplio cerro amesetado situado en la orilla derecha del río Tajo, cuando traza un amplio meandro, y está delimitado por barrancos con un curso de agua irregular. El yacimiento es conocido únicamente por prospección.

En superficie pudimos observar numerosísimos restos constructivos: tegulae, estucos, basas y fustes de columnas, muros, así como sillares almohadillados de grandes dimensiones e incluso restos de una estructura de canalización de aguas. Hay allí una ermita medieval, reformada en el siglo XVI, construida con sillares y columnas romanas.

El hábitat carpetano, que seguramente tuvo su origen en el siglo III antes de la Era, está representado por cerámicas a torno jaspeadas, con decoración monocroma de motivos geométricos (círculos concéntricos, bandas paralelas, melenas, etc...), con decoración estampillada, así como bordes de dolia y tinajas de almacenamiento de gran capacidad.

El poblamiento de época romana republicana queda atestiguado por la fíbula de la Tène final así como por las monedas de jinete lancero y signario paleohispánico a las que alude González (1999, 25), además de la cerámica de barniz negro. En total se han documentado 4 fragmentos de cerámica de barniz negro, dos hallados en las prospecciones antiguas y dos en las nuestras recientes.

Los dos primeros se corresponden con un galbo indeterminado de campaniense A media (190/180-100 a.C.) y un borde de barniz negro de Cales también de su fase media (130/120-90/80 a.C.) y que se trata de un cuenco similar a la serie 2974 de Morel. Los dos fragmentos hallados en las recientes prospecciones son un borde de campaniense A antigua (220-190/180 a.C.), sin barniz al interior y con un diámetro de 10 $\mathrm{cm}$ que hace pensar en una forma cerrada tipo guttus o lecitos y, el segundo, un pie de campaniense C (Fig. 3.3), de pasa gris y barniz negro de tacto jabonoso, con decoración en la parte superior del fondo a base de acanaladuras y estrías a ruedecilla, probablemente una copa Lamb. 17/ F 1255a 1 que podría fecharse a mediados del s. I a.C.

También hay que recordar la célebre ocultación argéntea encontrada en la vertiente sureste del cerro, fechada a comienzos del siglo II antes de la Era a partir de las piezas numismáticas (San Valero, 1945).

Sin embargo, el periodo de mayor esplendor del yacimiento parece corresponder a época imperial en los siglos I-II de la Era; entre los materiales documentados destaca un As de Calígula, terra sigillata itálica, terra sigillata gálica, terra sigillata hispánica lisa y decorada, común romana, cerámica pintada de tradición indígena y de paredes finas. Abascal (1982) situó en este lugar la mansio Caraca del Anónimo de Ravena.

- Bibliografía: Abascal, 1982, 79-81; González, 1999, 25-26; Sánchez-Lafuente, 1982, 109-114; San Valero, 1945 .

\section{OpPIDUM De La Merced - Muela de Taracena (TARACENA)}

Ubicado en la orilla izquierda del Henares en una meseta que forma una terraza al aproximarse al río, sin excesivo interés defensivo por ser fácilmente accesible desde el este, ha sido objeto de numerosas prospecciones. La única excavación sistemática desarrollada se realizó en 1977 por el la Asociación 


\begin{tabular}{|c|c|c|c|}
\hline YACIMIENTO & HALLAZGO & FORMAS & CRONOLOGÍA \\
\hline $\begin{array}{l}\text { 1. Los Rodiles (Cubillejo de } \\
\text { la Sierra) }\end{array}$ & $\begin{array}{l}\text { - Barniz negro de Cales } \\
\text { ( } 7 \text { frag.) } \\
\text { - Campaniense A (4 frag.) } \\
\text { - Ánfora }\end{array}$ & $\begin{array}{l}\text { - L5, L33b } \\
\text { - Morel 68, L5, L27ab o L27c } \\
\text { - Dressel 1 A }\end{array}$ & 190/180 a.C. $-90 / 80$ a.C. \\
\hline $\begin{array}{l}\text { 2. Villa de la Vega (Cubillejo } \\
\text { de la Sierra) }\end{array}$ & $\begin{array}{l}\text { - Barniz negro de Cales (1 } \\
\text { frag.) }\end{array}$ & - L3 & 130/120 a.C. $-40 / 20$ a. C. \\
\hline 3. Castil de Lobos (Alustante) & - Ánfora itálica (1 frag.) & - Dressel 1 & s. I a.C. \\
\hline $\begin{array}{l}\text { 4. Las Hoyas (Anquela del } \\
\text { Pedregal) }\end{array}$ & - Campaniense C (1 frag.) & - Indeterminada & s. I a.C. \\
\hline $\begin{array}{l}\text { 5. El Castillejo (Anquela del } \\
\text { Pedregal) }\end{array}$ & $\begin{array}{l}\text { - Barniz negro de Cales } \\
\text { (1 frag.) }\end{array}$ & $-\mathrm{L} 1 / 8$ & 130/120 a.C. $-40 / 20$ a.C. \\
\hline 6. Villarejo I (Morenilla) & $\begin{array}{l}\text { - Barniz negro indeterminado } \\
\text { (1 frag.) }\end{array}$ & - I ndeterminada & s. II-I a.C. \\
\hline 7. La Coronilla (Chera) & $\begin{array}{l}\text { - Barniz negro de Cales } \\
\text { - Campaniense A (22 frag. en } \\
\text { total Cales y A) } \\
\text { - Ánfora (1 frag.) }\end{array}$ & $\begin{array}{l}\text { - L4 y L5 } \\
\text { - Indeterminadas } \\
\text { - Dressel } 1\end{array}$ & s. II - I a.C. \\
\hline $\begin{array}{l}\text { 8. Necrópolis del Puente de la } \\
\text { Sierra (Checa) }\end{array}$ & $\begin{array}{l}\text { - Barniz negro de Cales? e } \\
\text { indeterminado ( } 5 \text { frag.) }\end{array}$ & $\begin{array}{l}\text { - L25 } \\
\text { - Oinochoe (forma no precisa, } \\
\text { uso funerario) }\end{array}$ & 220-100 a.C. \\
\hline 9. El Castillejo I (Terzaga) & $\begin{array}{l}\text { - Barniz negro de Cales } \\
\text { (1 frag.) }\end{array}$ & $-\mathrm{L} 1 / 8$ & 130/120 a.C. $-40 / 20$ a.C. \\
\hline 10. El Castellote (Corduente) & $\begin{array}{l}\text { - Barniz negro de Cales } \\
(1 \text { frag. })\end{array}$ & $-\mathrm{L} 5$ & 130/120 a.C. $-40 / 20$ a.C. \\
\hline 11. Las Coronillas I (Pardos) & - Campaniense C? & - L7 & s. I a. C. \\
\hline $\begin{array}{l}\text { 12. Hoyo Redondo II } \\
\text { (Anchuela del Campo) }\end{array}$ & $\begin{array}{l}\text { - Barniz negro de Cales } \\
\text { (1 frag.) } \\
\text { - Ánforas itálicas } \\
\text { (nº indeterminado). }\end{array}$ & $\begin{array}{l}\text { - L1 } \\
\text { - Indeterminadas }\end{array}$ & 130/120 a.C. $-40 / 20$ a.C. \\
\hline 13. La Torre II (Turmiel) & $\begin{array}{l}\text { - Barniz negro de Cales } \\
\text { indeterminado ( } 1 \text { frag.) }\end{array}$ & - Indeterminada & s. II-I a.C. \\
\hline 14. Modojos II (Codes) & - Ánfora itálica (1 frag.) & - Dressel 1 & s. I a.C. \\
\hline $\begin{array}{l}\text { 15. La Cerca (Aguilar de } \\
\text { Anguita) }\end{array}$ & $\begin{array}{l}\text { - Barniz negro de Cales } \\
\text { ( } 1 \text { plato }) \\
\left.\text { - Campaniense A ( } n^{\circ} \text { indet. }\right) \\
\end{array}$ & $\begin{array}{l}\text { - Plato (forma no precisa) } \\
\text { - Indeterminadas }\end{array}$ & s. II - I a.C. \\
\hline $\begin{array}{l}\text { 16. Tetas de Viana - } \\
\text { Teta Redonda (Viana de } \\
\text { Mondéjar) }\end{array}$ & $\begin{array}{l}\text { - Barniz negro de Cales } \\
\text { (2 frag.) }\end{array}$ & - L1?, L5 & 190/180 a.C. -100 a.C. \\
\hline $\begin{array}{l}\text { 17. Necrópolis de El Plantío } \\
\text { - El Almagral (Ruguilla, } \\
\text { Cifuentes) }\end{array}$ & -Ática? & - Kylix & S. IV a.C. \\
\hline $\begin{array}{l}\text { 18. Nuestra Señora de los } \\
\text { Huertos (Sigüenza) }\end{array}$ & - Campaniense $\mathrm{C}$ ( $\mathrm{n}^{\circ}$ indet.) & - Indeterminadas & s. I a.C. \\
\hline $\begin{array}{l}\text { 19. Muela de Alcocer } \\
\text { (Alcocer) }\end{array}$ & $\begin{array}{l}\text { - Barniz negro de Cales } \\
\text { (1 frag.) } \\
\text { - Campaniense A (2 frag.) } \\
\text { - Ánforas:itálica } \\
\text { ( }{ }^{\circ} \text { indeterminado), } \\
\text { levantina (2 frag.) y de } \\
\text { Brindisi } \\
\text { (1 frag.) }\end{array}$ & $\begin{array}{l}\text { - L5 y L6 } \\
\text { - Indeterminadas } \\
\text { - Dressel 1A e indeterminadas }\end{array}$ & s. II - I a.C. \\
\hline $\begin{array}{l}\text { 20. Necrópolis de } \\
\text { Valdenovillos (Alcolea de las } \\
\text { Peñas) }\end{array}$ & $\begin{array}{l}\text { - Barniz negro de Cales } \\
\text { (1 cuenco/bol) }\end{array}$ & - L1 & 130/120 a.C. $-40 / 20$ a.C. \\
\hline $\begin{array}{l}\text { 21. Cerro del Padrastro } \\
\text { (Santamera) }\end{array}$ & - Ática & - Indeterminada & s. IV a.C. \\
\hline 22. El Castro (Bujalaro) & $\begin{array}{l}\text { - Barniz negro indeterminado } \\
\text { (3 frag.) }\end{array}$ & - Indeterminadas & s. II - I a.C. \\
\hline
\end{tabular}




\begin{tabular}{|c|c|c|c|}
\hline $\begin{array}{l}\text { 23. Llano de San Pedro-Las } \\
\text { Viñas (Valderrebollo) }\end{array}$ & $\begin{array}{l}\text { - Barniz negro de Cales } \\
\text { (1 frag.) }\end{array}$ & $-\mathrm{L} 1$ & 90/80 a.C. $-40 / 20$ a.C. \\
\hline $\begin{array}{l}\text { 24. Cerro Alvarfañez } \\
\text { (Romanones) }\end{array}$ & - Campaniense C (1 frag.) & $-F 2310$ & s. I a.C. \\
\hline $\begin{array}{l}\text { 25. Vega del Tajo junto a } \\
\text { Valdealcalá - San Benito } \\
\text { (Almoguera) }\end{array}$ & - Campaniense C & - Indeterminada & s. I a.C. \\
\hline $\begin{array}{l}\text { 26. Cerro de la Virgen de la } \\
\text { Muela (Driebes) }\end{array}$ & $\begin{array}{l}\text { - Barniz negro de Cales } \\
\text { (1 frag.) } \\
\text { - Campaniense A (2 frag.) } \\
\text { - Campaniense C (1 frag.) }\end{array}$ & $\begin{array}{l}\text { - F2974 } \\
\text { - Guttus/lecitos? } \\
\text { - L17 }\end{array}$ & 220 a.C. - ca. 50 a.C. \\
\hline $\begin{array}{l}\text { 27. La Merced - Muela de } \\
\text { Taracena (Taracena) }\end{array}$ & $\begin{array}{l}\text { - Barniz negro de Cales } \\
\text { (1 frag.) } \\
\text { - Campaniense A, C } \\
\text { (no indet.) } \\
\text { - Ánfora greco-itálica (1 } \\
\text { frag.) }\end{array}$ & $\begin{array}{l}\text { - L8b } \\
\text { - Indeterminadas } \\
\text { - Indeterminada, tardía. }\end{array}$ & s. II - I a.C. \\
\hline 28. La Huelga (Alovera) & $\begin{array}{l}\text { - Barniz negro de Cales } \\
\text { (1 frag.) }\end{array}$ & $-\mathrm{L} 5$ & $220-190 / 180$ a.C. \\
\hline 29. La Guirmalda (Quer) & - Ánfora itálica (1 frag.) & - Dressel 1? & s. II - I a.C. \\
\hline
\end{tabular}

Figura 4: Resumen de hallazgos de cerámica de importación romana republicana en la provincia de Guadalajara.

Española de Amigos de la Arqueología (González et alii, 1977) que documentó una intersección de muros de viviendas, delimitando dos áreas con distinto suelo, uno de tierra apisonada y otro de tierra con gravilla incrustada; los muros estaban formados por zócalos de grandes piedras rodadas y aparecieron fragmentos de adobe asociados al alzado de los mismos. Igualmente encontraron tres fragmentos de cerámica a torno pintada con bandas marrones, otro decorado con semicírculos concéntricos, urnas de pasta gris y un fragmento de «campaniense $\mathrm{B}$ ».

En el Museo de Guadalajara hemos podido revisar los resultados de prospecciones antiguas, localizando un fragmento de barniz negro de Cales. Se corresponde probablemente con parte del fondo de un cuenco Lamb. $8 \mathrm{~b}$ de calena media. En cuanto a su decoración, presenta varios círculos concéntricos y una franja de estrías a ruedecilla, muy común en estos ejemplares. La cronología para la fabricación de esta producción se localiza entre el 130/120 - 90/80 a.C. También localizamos un fragmento de borde de ánfora greco-itálica tardía.

Las labores agrícolas han afectado gravemente los restos constructivos, observándose en superficie numerosos sillares y adobes y restos del recinto defensivo. En la bibliografía se afirma la existencia de un posible foso acerca del cual tenemos serias dudas y desde luego no pudimos confirmarla durante nuestras recientes prospecciones. En superficie encontramos cerámica carpetana decorada con pintura (círculos, bandas), cerámica estampillada, una fusayola sin decorar y otra de perfil cóncavo-cónico con estampillas triangulares repletas de puntos en relieve, a lo que habría que añadir que en la publicación de 1977 se menciona «la presencia de campaniense A, B y C en muy pequeñas cantidades».
La existencia de una ocultación de 168 denarios de bolskan y la aparición de bellotas de plomo con leyendas alusivas a Sertorio, permiten fijar el conflicto sertoriano como momento de abandono del hábitat, seguramente coincidiendo su destrucción con la campaña de Sertorio del año 77 a.C. La presencia de escasos fragmentos de T. S. H. en superficie hace pensar en una ocupación residual post-sertoriana del hábitat.

Es plausible que se trate del precedente de la mansio Arriaca (El Tesoro, Marchamalo) (Gamo, 2011b). - Bibliografía: Amitrano, 1983; Corral, 1987; Dávila, 2007, 114-115; Gamo, 2011b; Gil, 1980; González et alii, 1977; Stylow, 2005; Valiente, 1986; Valiente et alii, 1986.

\section{La Huelga (Alovera)}

Hábitat ubicado en una llanura sobre una de las terrazas en la margen derecha del río Henares, a una altitud de $620 \mathrm{~m} \mathrm{~s}$. n. m. Se conoce únicamente por prospección y no se conservan en superficie estructuras constructivas.

Parece que tuvo una ocupación muy prolongada en el tiempo: Edad de Bronce, I y II Edad de Hierro, con continuidad en época romana-republicana y en época altoimperial hasta el siglo II de la era. Del periodo bajo imperial solo hemos visto un fragmento, muy rodado, de T. S. H. T.

Las cerámicas son de varios tipos: a mano lisa, a torno oxidante y pintada de la II Edad del Hierro; de época romana un fragmento de cerámica de barniz negro, cerámica común romana, paredes finas, terra sigillata gálica y terra sigillata hispánica. Destacamos el fragmento de barniz negro, que hemos localizado en el 


\section{CERÁMICAS DE BARNIZ NEGRO}

VASOS PARA BEBER

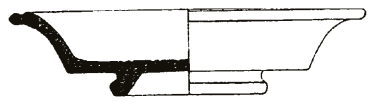

L17/F 1255a 1

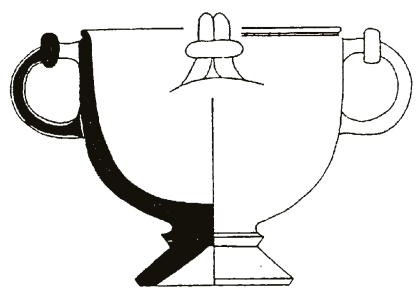

Morel 68/F 3131a 1

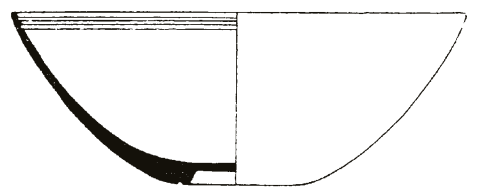

L22b/F 2153a 1
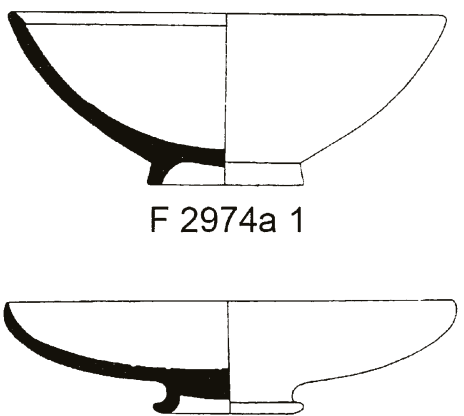

L8b/F 2243c 1

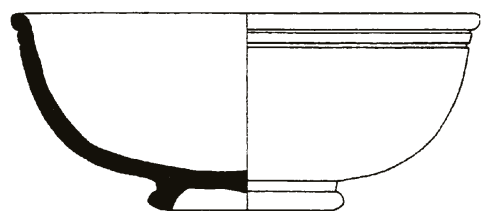

L1/8/F 2566a 1

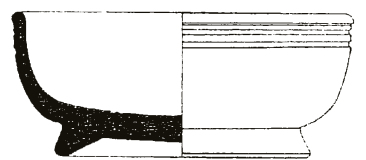

L1/F 2323a 1

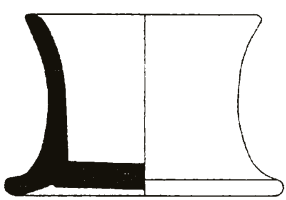

L3/F 7541a 1
PLATOS Y BOLES PARA CONSUMIR I PRESENTAR ALIMENTOS

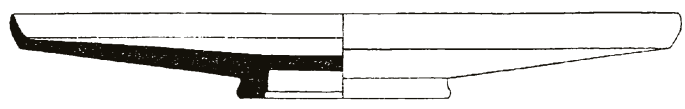

L7/F 2286a 1

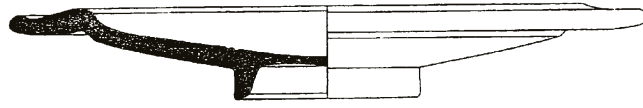

L6/F 1442j 1

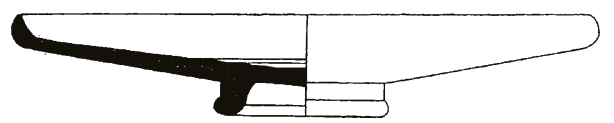

L5/F 2255a 1

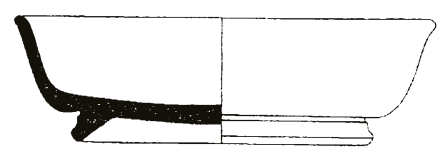

2311a 1

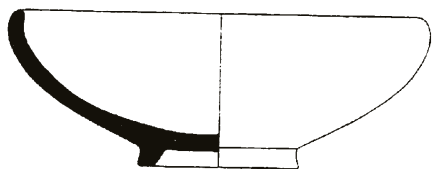

L27ab/F 2784d 3

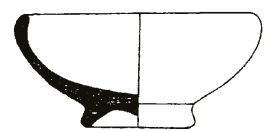

L25/F 2788c 1

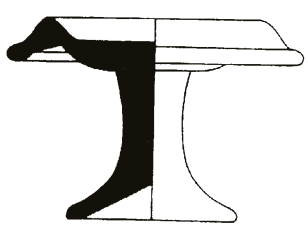

L4/F 1414a 1

Figura 5: Vajilla de barniz negro en la provincia de Guadalajara. 
Museo de Guadalajara, pues puede clasificarse como cerámica calena antigua (220-190/180 a.C.), probablemente del fondo de una pátera Lamb. 5 o similar.

- Bibliografía: Azcárraga, 2007, 338; Dávila, 2007, 112; Gutiérrez y Llanos, 1997.

\section{La Guirnalda (QueR)}

Este poblado está ubicado en una planicie entre dos afluentes del río Henares, el Narigón y Los Chorrillos, de 600 y $400 \mathrm{~m}$ de altitud respectivamente. Las únicas excavaciones arqueológicas realizadas fueron llevadas a cabo en el año $2007^{6}$ en una extensión total de $8546 \mathrm{~m} 2$.

La mayor parte de las estructuras excavadas son fosas o cubetas, algunas claramente identificadas como basureros y otras de difícil interpretación aunque destaca una cabaña rectangular, de $15,40 \mathrm{~m}$ de largo por 3,50 $\mathrm{m}$ de ancho, con las paredes de adobe y entramado vegetal sobre vigas de madera a modo de techumbre. Los materiales arqueológicos documentados se encuadran en un período cronológico desde el Bronce Final a la II Edad del Hierro.

En el conjunto cerámico documentado en el interior de la vivienda, predomina el torno sobre la mano y las formas más comunes son tinajillas finas con o sin decoración, seguidas por las ollas y cuencos; destaca la elevada proporción de cerámica decorada, bien con pintura, engobe, incisiones, acanaladuras, estampillas o una combinación de ellas. La cerámica de mesa también está presente, a través de platos, escudillas, jarras $\mathrm{y}$ varios caliciformes.

Entre la cerámica de importación destacan varios fragmentos cerámicos, aunque todos ellos en contextos de basurero: un borde de copita ática de barniz negro con un graffiti neo-púnico que suele asignarse al siglo IV a.C., aunque podría rebajarse en 50 o 100 años debido a su larga amortización en el centro de la Península Ibérica (Urbina et alii, 2005); otra cerámica de importación es un pivote de ánfora probablemente Dressel 1 (ss. II - I a.C.). También hay que destacar el hallazgo de dos fragmentos que parecen imitar la cerámica campaniense aunque no se traten en sentido estricto de cerámica de importación.

- Bibliografía: Azcárraga et alii, e.p.

\section{CONCLUSIONES}

El aumento del número de investigaciones con metodología rigurosa en este territorio celtibérico y carpetano ha permitido que se localicen y estudien gran cantidad de materiales de época romana republicana

6. Fueron dirigidas por la empresa Auditores de Energía y Medio Ambiente, S. L. y participó una de las firmantes (Azcárraga et alii, e. p.). $y$, aunque serán precisas muchas más intervenciones arqueológicas para llegar a una mejor comprensión del proceso de romanización en esta zona, esta actualización de los datos disponibles constituye un mejor punto de partida.

Se constata la llegada de producciones muy antiguas de cerámica de barniz negro, representada por las formas antiguas de campaniense A, a partir del 220 a.C., aunque también están presentes todas las demás formas posteriores; igualmente se documenta el barniz negro de Cales dedicado a la exportación desde sus formas más antiguas a las más recientes. La presencia de campaniense $\mathrm{C}$ es menos significativa debido a que su exportación no se realizó a gran escala, como sí ocurrió con las anteriores.

Aunque la cantidad de materiales importados aún es escasa, es de prever un aumento en su número si se sigue trabajando y esta tendencia que apuntamos se está demostrando también en otras zonas cercanas del interior meseteño, como en el yacimiento carpetano de El Llano de la Horca (Santorcaz), en el cual se han documentado más de 100 fragmentos de barniz negro a lo largo de las intensivas campañas de excavación (Azcárraga, 2007, 338).

Como ha quedado evidenciado, el material importado de cronología romano-republicana se distribuye por toda la provincia de Guadalajara. No entraremos a valorar «vacíos» ni concentraciones, puesto que la desigual intensidad de las tareas arqueológicas desarrolladas en los distintos ámbitos geográficos estudiados hace que dichas observaciones carezcan de validez científica.

Por el contrario, las formas cerámicas parecen asociarse en la mayoría de los casos a redes de distribución vinculadas al valle del Ebro y ello es interesante porque la existencia de contactos comerciales entre los valles del Tajo y el Henares con el medio Ebro se documenta también en la circulación numismática (Abascal, 1995, 174), al igual que la posterior red viaria romana imperial seguirá las mismas rutas.

Por todo lo antedicho, sintetizamos los aspectos más destacados que el estudio de las cerámicas permite esbozar sobre la romanización de estos territorios:

- La presencia de estos materiales importados en numerosos yacimientos indígenas no significa necesariamente la total romanización de dichos lugares, pero sí indica la temprana presencia de Roma en la Meseta y su interés por conseguir determinados productos a través de circuitos y redes comerciales estables, sobre las que todavía hay que seguir trabajando para valorar correctamente su grado de imbricación en el territorio ocupado.

- La cronología temprana de alguna de estas cerámicas, presentes en hábitats carpetanos y celtibéricos desde finales siglo III- comienzos siglo II a.C., parece indicar a la existencia de redes de intercambio en los primeros momentos de la conquista romana, incluso antes de las primeras operaciones militares en este territorio. 
- Estos objetos importados se han considerado tradicionalmente como «elementos de prestigio» lo cual indicaría la voluntad de las élites locales por asimilarse al nuevo poder en sus usos externos. Llama la atención que la gran mayoría de las formas de cerámica de barniz negro documentadas son recipientes destinados a su uso en la mesa (Pérez, 2007:210), bien para beber o bien para servir/ presentar o consumir alimentos (Fig. 5).

- Una visión poco detallada del registro arqueológico de los hábitats y necrópolis de los siglos II-I a.C. de la provincia puede proporcionar una apariencia de contextos poco romanizados y con características formales más vinculadas a la etapa precedente (tipo de fortificaciones, espacios habitacionales, ritual funerario, mayoría de cerámicas autóctonas, etc...). Sin embargo, un estudio detallado de las cerámicas romanas demuestra su presencia en un gran número de poblados y algunas necrópolis; estas últimas resultan especialmente relevantes puesto que los entornos funerarios siempre tienen un carácter muy conservador y esta presencia muestra la penetración temprana de los gustos itálicos en muchos aspectos de la vida cotidiana de los grupos indígenas meseteños.

\author{
Emilio Gamo Pazos \\ Dpto. de Prehistoria y Dpto. de Historia Antigua \\ Facultad de Geografía e Historia \\ Universidad Complutense de Madrid \\ Ciudad Universitaria \\ 28040 Madrid \\ emiliogamo@hotmail.com \\ Sandra Azcárraga Cámara \\ Dpto. de Prehistoria y Arqueología \\ Universidad Autónoma de Madrid \\ Campus de Cantoblanco \\ 28049 Madrid \\ sandra.azcarraga@gmail.com
}

\section{BIBLIOGRAFÍA}

ABASCAL, J. M., 1982: Vías de comunicación romanas de la Provincia de Guadalajara, Guadalajara.

ABASCAL, J. M., 1995: «Excavaciones y hallazgos numismáticos de Fernando Sepúlveda en Valderrebollo (1877-1879), Wad-Al-Hayara, 22, 151-174.

AGUILERA, E., 1916: Las necrópolis ibéricas, Madrid.

AMITRANO, R., 1983: «El tratamiento de conservación de un vaso cerámico celtibérico», Homenaje al Profesor Martín Almagro Basch. Volumen III, 143-150, Madrid.

AQUILUÉ, X.; GARCÍA, J. y GUITART, J., (Coord.), 2000: La cerámica de vernís negre dels segles II i I a.C.: Centres productors mediterranis i comercialització a la Península Ibèrica. Taula rodonda. (Empúries, 1998), Museu de Mataró.

ARENAS, J. A., 1993: «El poblamiento de la Segunda Edad de Hierro en la depresión Tortuero-La Yunta (Guadalajara)», Complutum, 4, 279-296.
ARENAS, J. A., 1998: La Edad del Hierro en el extremo oriental de la meseta: los páramos y sierras de Molina de Aragón; Tesis doctoral, Universidad Complutense de Madrid.

ARENAS, J. A., 1999: La Edad del Hierro en el Sistema Ibérico Central, British Archaeological Reports (Jonhn \& Erica Hedges, Eds.), International Series 780, Oxford.

ARGENTE, J. L., 1977: «Los yacimientos de la colección Cerralbo a través de los materiales conservados en los fondos del Museo Arqueológico Nacional», en XIV Congreso Arqueológico Nacional, 587-598, Zaragoza.

ARGENTE, J. L., 1994: Las fíbulas de la Edad de Hierro en la Meseta Oriental, Excavaciones Arqueológicas en España, 168, Madrid.

ASENSIO, D. y PRINCIPAL, J., 2006: «Relaciones comerciales Roma-Hispania. La Hispania Citerior en el siglo II a.C.», en F. BURILLO (Coord.), Segeda y su contexto histórico: Entre Catón y Nobilior (195 al 153 a.C.), Homenaje a Antonio Beltrán Martínez, 117-140, Zaragoza.

AZCÁRRAGA, S., 2007: «El inicio de la romanización en la región madrileña: nuevas perspectivas para la investigación» en Estudios sobre la Edad de Hierro en la Carpetania. Registro arqueológico, secuencia y territorio. Volumen I, Zona Arqueológica, 10, 88-135, Alcalá de Henares.

AZCÁRRAGA, S., MORÍN, J. y URBINA, D., 2008: «Conjunto cerámico de una estructura doméstica de Segunda Edad del Hierro en el yacimiento de la Guirnalda (Quer)», Segundo Simposio AUDEMA. El Primer milenio a.C. en la Meseta Central (en prensa).

BARRIL, M y DÍAZ, V., 1998: «Reexcavando Aguilar de Anguita a través de los documentos escritos y los materiales depositados en el M. A. N.», Kalathos, 17, 47-90.

BOSCH, P., 1921: «Los celtas y la civilización céltica en la Península Ibérica», Boletín de la Sociedad Española de Excursiones, 39, 248-301.

CABRÉ, J., 1920: «La necrópolis de Tútugi», Boletín de la Sociedad Española de Excursiones, Madrid.

CEÁN-BERMÚDEZ, J. A., 1832: Sumario de las Antigüedades romanas que hay en España en especial las pertenecientes a las Bellas Artes, Madrid.

CERDEÑO, M. L., 1976: «La necrópolis celtibérica de Valdenovillos (Guadalajara)», Wad-Al-Hayara, 3, 5-26.

CERDEÑO, M. L. y GARCÍA-HUERTA, R., 1982: «Avance de la estratigrafía protohistórica de la Coronilla (Molina de Aragón, Guadalajara)», Noticiario Arqueológico Hispánico, 14, 255-300.

CERDEÑO, M. L. y GARCÍA-HUERTA, R., 1992: El castro de La Coronilla. Chera, Guadalajara (19801986), Excavaciones Arqueológicas en España, 163, Madrid.

CERDEÑO, M. L., SAGARDOY, T., CHORdÁ, M. y GAMO, E., 2008: «Fortificaciones celtibéricas frente a Roma: El oppidum de los Rodiles (Cubillejo de la Sierra, Guadalajara)», Complutum, 19, 173-189.

CERDEÑO, M. L., CHORDÁ, M. y GAMO, E., 2010: «El oppidum de Los Rodiles: los celtíberos frente a Roma» 
en M. NAVARRO (Coord.), Actas del V Coloquio Internacional: Conflicts et sociétés en Hispanie à l'époque de la conquête romaine (III-I siècle av.J.C.), (Université Bordeaux III, 25-27 Noviembre 2010), Ausonius. Institut de Recherche sur 1' Antiquité et le Moyen Âge, (en prensa).

CERDEÑO, M. L. y GAMO, E., 2009: «La necrópolis de época visigoda de Cubillejo de la Sierra (Guadalajara)», en Actas del Primer Congreso Internacional sobre «Espacios Urbanos en el Occidente Mediterráneo, siglos VI-VIII (Toledo del 30 de Septiembre al 3 de Octubre de 2009), (en prensa).

CORRAL, M., 1987: «Aspectos socio-económicos del poblamiento durante el primer milenio a.C. en la zona media de Guadalajara», Wad-Al-Hayara, 14, 35-59.

DÁVILA, A. F., 2007: «La Edad de Hierro en el bajo valle del Henares: territorio y asentamientos», en Estudios sobre la Edad de Hierro en la Carpetania, registro arqueológico, secuencia y territorio. Volumen I, Zona Arqueológica, 10, 88-135, Alcalá de Henares.

FERRERO, S. y GARCÍA-SOTO, E., 2007: «Excavaciones arqueológicas en el atrio de la iglesia de Nuestra Señora de Los Huertos (Sigüenza, Guadalajara)», en J. M. MILLÁN y C. RODRÍGUEZ (Coords.), Arqueología de Castilla-La Mancha, Actas de las I Jornadas (Cuenca 13-17 de Diciembre de 2005), 615-639, Cuenca.

FUENTES, A., 1993: «Las ciudades romanas de la Meseta Sur», en Catálogo general de la ciudad Hispanorromana, 159-189, Madrid.

GAMO, E., 2009: Informe del proyecto: Catalogación e Inventario de Yacimientos Romanos de la provincia de Guadalajara a partir de los materiales conservados en el Museo Provincial, Informe inédito.

GAMO, E., 2011: Memoria del proyecto: La época romana republicana en la actual Provincia de Guadalajara: siglos II-I a.C., Informe inédito, Guadalajara.

GAMO, E., 2011b: «El conflicto sertoriano en la actual provincia de Guadalajara. La arqueología y las fuentes», II Jornadas de jóvenes en Investigación Arqueológica (Universidad Complutense de Madrid, 6-8 de Mayo de 2009), Tomo I, 179-186, Zaragoza.

GARCÍA, A., 1936: Los hallazgos griegos de España, Centro de Estudios Históricos, Fichero de Arte Antiguo, Madrid.

GARCÍA, A., 1964: «Memoria de las actividades arqueológicas llevadas a cabo en el Distrito Universitario de Madrid durante el año 1962», Noticiario Arqueológico Hispánico, 6, 358-362.

GARCÍA-HUERTA, M. R., 1989: "Castros inéditos de la Edad de Hierro en las parameras de Molina de Aragón (Guadalajara)», Wad-Al-Hayara, 16, 7-30.

GARCÍA-HUERTA, M. R., 1990: La Edad del Hierro en la Meseta Oriental: el alto Jalón y el alto Tajo, Colección Tesis Doctorales, 50/90, Madrid.

GARCÍA-HUERTA, R. y CERDEÑO, M. L., 1986-1987: «Estructuras de habitación del poblado de la Coronilla (Molina de Aragón, Guadalajara)», Zephyrus, 39-40, 37-345.
GUTIÉRREZ, A. y LLANOS, R., 1997: Inventario de la Carta Arqueológica de Castilla-La Mancha. Alovera, Informe inédito, DGPYM.

GIL, O., 1980: «Tesoro de denarios hispanorromanos descubierto en la Muela de Taracena (Guadalajara)», WadAl-Hayara,: 206-216.

GONZÁLEZ, C., 1999: Fíbulas en la Carpetania, Madrid.

GONZÁLEZ, C., ORTEGA, L. e IGLESIAS, M., 1977: «Descubrimiento de una ocultación de denarios ibéricos en el término de Guadalajara», Boletín de la Asociación Española de Amigos de la Arqueología, 8, 28-33.

GORGUES, A. y RUBIO, R., 2010: «Aguilar de Anguita: 1' apport des nouvelles fouilles», en M. NAVARRO (Coord.), Actas del V Coloquio Internacional: Conflicts et sociétés en Hispanie à l'époque de la conquête romaine (III-I siècle av.J.C.), (Université Bordeaux III, 25-27 Noviembre 2010), Ausonius. Institut de Recherche sur l' Antiquité et le Moyen Âge, (en prensa).

HUAGÓN, F. R., 1893: «Antigüedades romanas de La Alcarria. Gárgoles de Arriba», Boletín de la Real Academia de la Historia, 23, 346-350.

LÁZARO, I., 1993-95: «Los materiales islámicos de <El Turmielo> (Aragoncillo, Guadalajara)», Kalathos, 1314, 133-141.

LÓPEZ, J. R., 1985: Terra Sigillata Hispánica tardía decorada a molde en la Península Ibérica, Salamanca.

LORRIO, A. J., 2001: Ercávica. La muralla y la topografia de la ciudad, Bibiotheca Archeologica Hispana, 9, Madrid.

MALUQUER, J., 1954: «La Edad del Hierro en la cuenca del Ebro y en la Meseta central española», en IV Congreso de Ciencias Prehistóricas y Protohistóricas, Madrid.

MARTÍNEZ, J. P. y DE LA TORRE, J. I., 2008: «La necrópolis celtibérica de Puente de la Sierra (Checa, Guadalajara)», E. GARCÍA-SOTO, M. A. GARCÍA y J. P MARTÍNEZ, Actas del Segundo Simposio de Arqueología de Guadalajara, (Molina de Aragón, 20-22 de Abril de 2006), 175-192, Guadalajara.

MARTÍNEZ, V. y VALIENTE, J., 1990: «Un asentamiento campaniforme en las Tetas de Viana (Viana de Mondéjar, Guadalajara)», Wad-Al-Hayara, 17, 7-42.

PAVÓN, B., 1984: Guadalajara medieval. Arte y Arqueología Árabe y Mudéjar, C. S. I. C, Madrid.

PÉREZ, J., 2007: «La cerámica de barniz negro como mercancía. Comercio y redistribución en Hispania», Actas $V$ Jornadas Internacionales de Arqueología Subacuática, 209-207. Valencia

PÉREZ, A., 1974: Alcocer: historia y arte, Guadalajara.

SÁNCHEZ-LAFUENTE, J., 1979: «Aportaciones al estudio del campamento romano de $<$ La Cerca $>$ (Aguilar de Anguita, Guadalajara)», Wad-Al-Hayara, 6, 77-83.

SÁNCHEZ-LAFUENTE, J., 1982: «Nuevos yacimientos romanos en la provincia de Guadalajara», Wad-Al-Hayara, 9, 103-115.

SÁNCHEZ-LAFUENTE, J., 1987: «La epigrafía y el entorno arqueológico de la villa romana de Gárgoles de Arriba (Guadalajara)», Lucentum, 7, 175-182.

SAN VALERO, J., 1945: El tesoro preimperial de plata de Driebes (Guadalajara), Informes y Memorias de la 
Comisaría General de Excavaciones Arqueológicas, 9, Madrid.

SCHÜLE, W., 1969: Die Meseta-Kulturen der Iberischen Halbinsen, Berlín.

SCHULTEN, A., 1929: Deustche Zeitung für Spanien, Barcelona.

STYLOW, A. U., 2005: «Fuentes epigráficas para la historia de la Hispania Ulterior en época republicana» en E. MELCHOR ET ALII (Coords.), Julio César y Corduba: tiempo y espacio en la campaña de Munda (49-45 A.C.), Actas del Simposio organizado por la Facultad de Filosofía y Letras de la Universidad de Córdoba y Departamento de Ciencias de la Antigüedad y de la Edad Media, 247-262, Córdoba.
VALIENTE, J., 1986: «Colgantes y amuletos hallados en las terreras del río Henares», Trabajos de Prehistoria, 43, 195-209.

VALIENTE, J., 1992: «El cerro del Padrastro en Santamera y la Protohistoria del Valle del Henares», en J. VALIENTE (Ed.), La celtización del Tajo Superior, 11-44, Alcalá de Henares.

VALIENTE, J., 1997: Guía de la Arqueología de Guadalajara, Guadalajara.

VALIENTE, J., CRESPO, M. L. y ESPINOSA, C., 1986: «Un aspecto de la celtización en el alto y medio Henares. Los poblados de ribera», Wad-Al-Hayara, 13, 47-70.

VALIENTE, J. y VELASCO, M., 1988: «Yacimiento de tipo Riosalido. Ermita de la Vega, Cubillejo de la Sierra, Guadalajara», Wad-Al-Hayara, 15, 95-121. 